\title{
Vírus-T linfotrópico humano em familiares de candidatos a doação de sangue soropositivos: disseminação silenciosa
}

\author{
Bernadette Catalan-Soares, ${ }^{1}$ Anna Bárbara Carneiro-Proietti, ${ }^{1}$ \\ Fernando Augusto Proietti ${ }^{2}$ e Grupo Interdisciplinar de Pesquisas em HTLV
}

Como citar Catalan-Soares B, Carneiro Proietti AB, Proietti FA, Grupo Interdisciplinar de Pesquisas em HTLV. Vírus-T linfotrópico humano em familiares de candidatos a doação de sangue soropositivos: disseminação silenciosa. Rev Panam Salud Publica. 2004;16(6):387-94.

RESUMO Objetivo. Verificar a ocorrência de transmissão do vírus-T linfotrópico humano entre familiares de portadores assintomáticos, identificados por ocasião de doação de sangue; e avaliar a provável direção da transmissão em parceiros sexuais com o mesmo diagnóstico sorológico (concordantes).

Métodos. Entre março de 1997 e junho de 2003 foram estudados familiares e parceiros sexuais estáveis de doadores de sangue soropositivos (e assintomáticos) para o vírus-T linfotrópico humano dos tipos I e II. O diagnóstico foi obtido pelos testes imunoenzimático e Western blot. Para determinar a direção da transmissão, foram coletados, através de um questionário, dados demográficos e comportamentais. Os participantes do estudo residiam na região metropolitana de Belo Horizonte, capital do Estado de Minas Gerais.

Resultados. A soroprevalência geral para o vírus-T linfotrópico humano do tipo I foi de 25,9\% entre 352 familiares de 343 pacientes soropositivos (334 positivos para o tipo I e 9 positivos para o tipo II). Em mães, parceiros sexuais e filhos de doadores soropositivos a prevalência foi de 36,6\% (15/41), 35,9\% (42/117) e 17,5\% (34/194), respectivamente. Os dados obtidos acerca de fatores de risco indicaram maior eficiência de transmissão no sentido do homem para a mulher.

Conclusões. As taxas de prevalência sugerem agregação familiar da infecção por vírus-T linfotrópico humano. A transmissão se deu principalmente por via sexual (horizontal). Devese avaliar a presença do vírus em pessoas relacionadas a indivíduos infectados, mesmo se assintomáticos, para melhor compreensão da transmissão e implementação de medidas mais eficazes de prevenção contra a disseminação do vírus.

Palavras-chave Epidemiologia, HTLV-I, HTLV-II, núcleo familiar.

1 Fundação Hemominas, Belo Horizonte (MG), Brasil. Enviar correspondência para Bernadette Catalan-Soares no seguinte endereço: Alameda Ezequiel Dias 321, Funcionários, CEP 30130-110, Belo Horizonte, MG, Brasil. Fone: +55-31-32484587; fax: +55-31-3248-4600; e-mail: pesquisa@ hemominas.mg.gov.br

2 Universidade Federal de Minas Gerais (UFMG), Faculdade de Medicina, Belo Horizonte (MG), Brasil.
$\mathrm{O}$ vírus-T linfotrópico humano do tipo I (HTLV-I), o primeiro retrovírus humano a ser identificado (1), tem sido associado epidemiologicamente a leucemia de células T do adulto, paraparesia espástica tropical, polimiosite, artrites, uveíte, lesõe dermatológicas e estrongiloidíase, entre outras doenças (2-7). O tipo II foi identificado em 1982 (8) e compartilha $66 \%$ do genoma com o tipo I. Contudo, ainda não está claramente associado a patologias, embora existam relatos de sua co-ocorrência com doenças neurológicas semelhan- 
tes às associadas ao HTLV-I (9). Globalmente, se estima que entre 10 e 20 milhões de pessoas estejam infectadas pelo HTLV-I (10).

A presença do HTLV-I e II na América do Sul está bem estabelecida, embora sua origem e distribuição no continente não estejam completamente esclarecidas (11). Vários estudos conduzidos entre doadores de sangue no Estado de Minas Gerais, Brasil, mostraram prevalência média de $0,4 \%$ nessa população (12). Outro estudo envolvendo candidatos a doação de sangue em Minas Gerais identificou a transfusão de sangue, a baixa escolaridade e o uso de maconha como determinantes associados à soropositividade nessa população de baixo risco para retroviroses (13). Os modos de infecção são comuns ao HTLV I e II, e incluem a transmissão vertical, principalmente através da amamentação; a transmissão parenteral, por transfusão de componentes celulares do sangue e compartilhamento de agulhas e seringas por usuários de drogas endovenosas; e a transmissão sexual, com maior eficiência no sentido homem-mulher $(14,15)$.

Mais de duas décadas após a identificação do HTLV-I foi possível descrever um evidente padrão epidemiológico: tendência a agregação em diferentes áreas geográficas no mundo, variação de prevalência em regiões geográficas distintas, aumento da prevalência com a idade, maior soroprevalência no sexo feminino e agregação familiar da infecção e de patologias relacionadas ao vírus. Vários investigadores encontraram evidência dessa agregação e consideram a possibilidade de fatores outros, além das vias naturais de transmissão, para justificar as altas taxas de prevalência intrafamiliares: fatores genéticos, como por exemplo perfil dos antígenos leucocitários humanos (HLA), conferindo proteção ou predisposição para o desenvolvimento de patologias relacionadas ao HTLV-I; fatores relacionados ao vírus, tais como carga proviral e virulência; fatores ambientais e práticas culturais, como a escarificação da pele com agulhas e facas não esterilizadas, que é comum em população da Nigéria; e a interação desses fatores (16-26).
No Brasil, a triagem para HTLV-I e II tornou-se obrigatória em bancos de sangue em novembro de 1993. Cerca de 0,5\% dos doadores de sangue no país apresentam sorologia positiva, com ampla predominância do tipo I (27). Em Minas Gerais, desde 1997 o Grupo Interdisciplinar de Pesquisas em HTLV (GIPH) avalia prospectivamente candidatos a doação de sangue soropositivos para HTLV-I e II, pacientes com mielopatia associada ao HTLV-I atendidos em hospital especializado (Rede SARAH de Hospitais do Aparelho Locomotor) e familiares dos dois grupos. O GIPH acompanha um dos maiores grupos de indivíduos infectados pelo HTLV-I na atualidade, e pretende seguir essa coorte prospectivamente até 2017, com avaliações bianuais.

O objetivo do presente estudo foi investigar as taxas e vias de transmissão nos familiares e parceiros sexuais dos candidatos a doação de sangue soropositivos participantes da coorte GIPH. Também procurou-se determinar a direção provável da infecção nos parceiros sexuais infectados com diagnósticos concordantes.

\section{MATERIAIS E MÉTODOS}

Minas Gerais localiza-se na Região Sudeste do Brasil. Ocupa uma área de $586624 \mathrm{~km}^{2}$ e tem uma população de 18 milhões de habitantes, $82 \%$ dos quais vivem em zonas urbanas. A prevalência média da infecção pelo HTLV é de $0,1 \%$, considerando a população de candidatos a doação soropositivos que vivem na capital do Estado, Belo Horizonte.

A coorte aberta prevalente GIPH acompanha indivíduos soropositivos diagnosticados por ocasião de doação de sangue nessa região, objetivando uma maior compreensão de aspectos epidemiológicos, clínicos e laboratoriais associados ao vírus. $\mathrm{O}$ presente estudo se refere a esse grupo, que compreende 343 sujeitos soropositivos e 236 soroindeterminados para HTLV-I e II. Apenas nove indivíduos estão infectados pelo HTLV tipo II. Somente dois casos de infecção por ambos os tipos foram identificados. A grande maioria, portanto, está infectada pelo HTLV-I.

Os doadores soropositivos da coorte GIPH foram estimulados a recrutar seus familiares e parceiros sexuais estáveis para serem testados sorologicamente para a presença do HTLV-I e II. Assim, familiares próximos (pais, irmãos e filhos) e parceiros sexuais atuais, com mais de 6 meses de relacionamento, foram elegíveis para participação no estudo. Se constatada a soropositividade, eram convidados a fazer parte do estudo prospectivo, seguindo o mesmo protocolo dos doadores infectados.

Foram testados sorologicamente 452 familiares e parceiros sexuais de 343 pacientes soropositivos e 236 soroindeterminados. Dados demográficos e comportamentais foram obtidos através de questionário estruturado, administrado após obtenção do consentimento livre e esclarecido. O projeto do presente estudo foi aprovado pelo Comitê de Ética em Pesquisa da Fundação Hemominas.

\section{Métodos laboratoriais e sorologia para HTLV}

As amostras de sangue dos participantes foram testadas para anticorpos anti-HTLV por método imunoenzimático (ELISA), Western blot (WB) e reação em cadeia da polimerase (PCR). Os candidatos aptos à triagem clínica foram encaminhados à sala de coleta, onde foi colhida a bolsa de sangue conforme padrões técnicos especificados pelo Ministério da Saúde. Ao final desse procedimento foi colhida amostra de sangue e enviada ao laboratório de sorologia da Fundação Hemominas para realização dos testes de hepatite $B$ e C, sífilis, doença de Chagas, HIV e HTLV. No caso específico do HTLV, os indivíduos que apresentaram reação ao teste de triagem (ELISA) foram convocados para coleta de uma segunda amostra, ocasião na qual foi repetido o teste ELISA e realizado o exame confirmatório (WB). Foram consideradas como positivas para HTLV-I ou II as amostras reativas a proteínas do gene gag (p19 ou p24) e 
do gene env (gp 46 e GD21). A diferenciação entre tipo I e II foi feita pelo $\mathrm{WB}$, através de proteínas recombinantes do env (rgp 46-I ou rgp 46-II), e pelo PCR.

\section{Análise de fatores de risco para direção da transmissão sexual}

Para avaliar a provável direção da infecção em pares concordantes (onde ambos os parceiros apresentavam o mesmo diagnóstico sorológico), verificamos a presença de fatores de risco principais ou secundários, de acordo com questionário formulado pelos epidemiologistas do GIPH e validado em projeto piloto. O questionário foi aplicado por entrevistador treinado, em ambiente de privacidade. Foram considerados como fatores de risco principais: transfusão de sangue antes de 1994, uso de drogas injetáveis, ter sido amamentado por mãe ou ama-de-leite atualmente soropositiva, ter praticado sexo pago e ter tido 10 ou mais parceiros sexuais na vida. Os fatores secundários incluíram: de dois a 10 parceiros sexuais na vida ou uso de drogas ilegais não-injetáveis.

A direção homem-mulher foi considerada provável se a mulher não apresentasse fator de risco e o homem apresentasse pelo menos um dos fatores de risco principais ou dois fatores de risco secundários; ou se a mulher apresentasse um dos fatores de risco secundários e o homem apresentasse fator de risco principal. Também foi considerada como indicativa de direção homem-mulher a situação em que o homem era soropositivo e a mulher soroindeterminada com conversão posterior. Em circunstâncias opostas, foi considerada como provável a direção mulher-homem. Para pares concordantes que não preencheram esses critérios, a direção da transmissão foi considerada incerta.

Para avaliar os fatores de risco para transmissão entre casais, os pares concordantes foram comparados aos pares discordantes (parceiros com diagnósticos diferentes entre si) em termos dos dados levantados pelo questionário.

\section{RESULTADOS}

As análises sorológicas feitas em amostras de 352 familiares de doadores com sorologia positiva para HTLV-I identificaram $91(25,9 \%)$ soropositivos e três $(0,9 \%)$ soroindeterminados, quando considerados globalmente mães, filhos e parceiros sexuais. Para 100 familiares de soroindeterminados, foram identificados dois $(2,0 \%)$ soropositivos e dois $(2,0 \%)$ soroindeterminados. Os resultados acerca dos indivíduos positivos para HTLV-I são detalhados na tabela 1 , onde se observa uma clara associação entre a infecção e os parceiros sexuais soropositivos e entre a infecção e as mães soropositivas quando são comparados os familiares dos soropositivos aos familiares dos indeterminados. Quando os membros da família foram considerados em conjunto, verificamos agregação familiar da soropositividade.

De nove sujeitos positivos para HTLV-II, cinco tinham parceiros sexuais estáveis. Destes, quatro (80\%) foram testados. Dentre os testados, um (25\%) foi também soropositivo para o subtipo II. Uma portadora do HTLV-II amamentou três filhas; dessas filhas, uma $(33,3 \%)$ foi positiva para o tipo II e as outras duas foram soronegativas para o HTLV-I e II. O tempo de ama- mentação foi superior a 6 meses para as três filhas e apenas a caçula adquiriu o vírus. Contudo, não se pode inferir que a mãe tenha sido infectada entre a segunda e a terceira gestação, já que a transmissão não ocorre em $100 \%$ dos casos e parece estar associada à carga proviral. As filhas soronegativas podem ter sido amamentadas em fase de baixa carga.

\section{Transmissão horizontal}

Um total de 343 doadores soropositivos (figura 1) foram considerados neste estudo. Desses, 64,1\% (220) relataram ter parceiro sexual estável no momento, sendo 53,6\% (118/220) homens e $46,4 \%(102 / 220)$ mulheres. Entre os casais, 55,0\% (121/220) dos indivíduos recrutaram seus companheiros para serem testados, sendo homens $47,1 \%$ (57/121) e $52,9 \%$ mulheres $(64 / 121)$. Noventa e nove parceiros sexuais não foram testados, ou por não terem sido recrutados ou por recusa em participar, caracterizando uma perda de $45,0 \%(99 / 220)$.

Das mulheres parceiras dos doadores soropositivos para o tipo I, $43,6 \%$ $(24 / 55)$ foram positivas. Dos homens parceiros das doadoras positivas para o

TABELA 1. Positividade para HTLV-I em familiares de candidatos a doação de sangue soropositivos e soroindeterminados, Belo Horizonte (MG), Brasil, 1997 a 2003

\begin{tabular}{lcccc}
\hline \multicolumn{1}{c}{ Relação } & $\begin{array}{c}\text { Positivo } \\
\text { No. }(\%)\end{array}$ & $\begin{array}{c}\text { Indeterminado } \\
\text { No. }(\%)\end{array}$ & OR (IC95\%) & $P$ \\
\hline Mães & & & & \\
$\quad$ Positivas para HTLV-I & $15(36,6)$ & $1 / 12(8,3)$ & $6,35(0,71$ a 144,50) & 0,05 \\
Negativas para HTLV-I & 26 & 11 & & \\
$\quad$ Total & 41 & 12 & & 0,07 \\
Filhos & $34(17,5)$ & 0 & Indefinido & \\
Positivos para HTLV-I & 160 & 14 & & \\
Negativos para HTLV-I & 194 & 14 & & \\
$\quad$ Total & $42(35,9)$ & $1(1,4)$ & $40,88(5,81$ a 819,59$)$ & $<0,01$ \\
Parceiros sexuais & 75 & 73 & & \\
Positivos para HTLV-I & 117 & 74 & & \\
Negativos para HTLV-I & & & & \\
$\quad$ Total & $91(25,9)$ & $2(2,0)$ & $17,08(4,04$ a 102,2) & $<0,01$ \\
Todos os membros da família & 261 & 98 & & \\
Positivos para HTLV-I & 352 & 100 & & \\
Negativos para HTLV-I & & & & \\
$\quad$ Total & & & & \\
\hline
\end{tabular}

\footnotetext{
a HTLV-I: vírus-T linfotrópico humano tipo I.
} 
FIGURA 1. Transmissão sexual entre portadores de HTLV I e II, Belo Horizonte (MG), Brasil, $1997{\text { a } 2003^{\mathrm{a}}}^{2}$

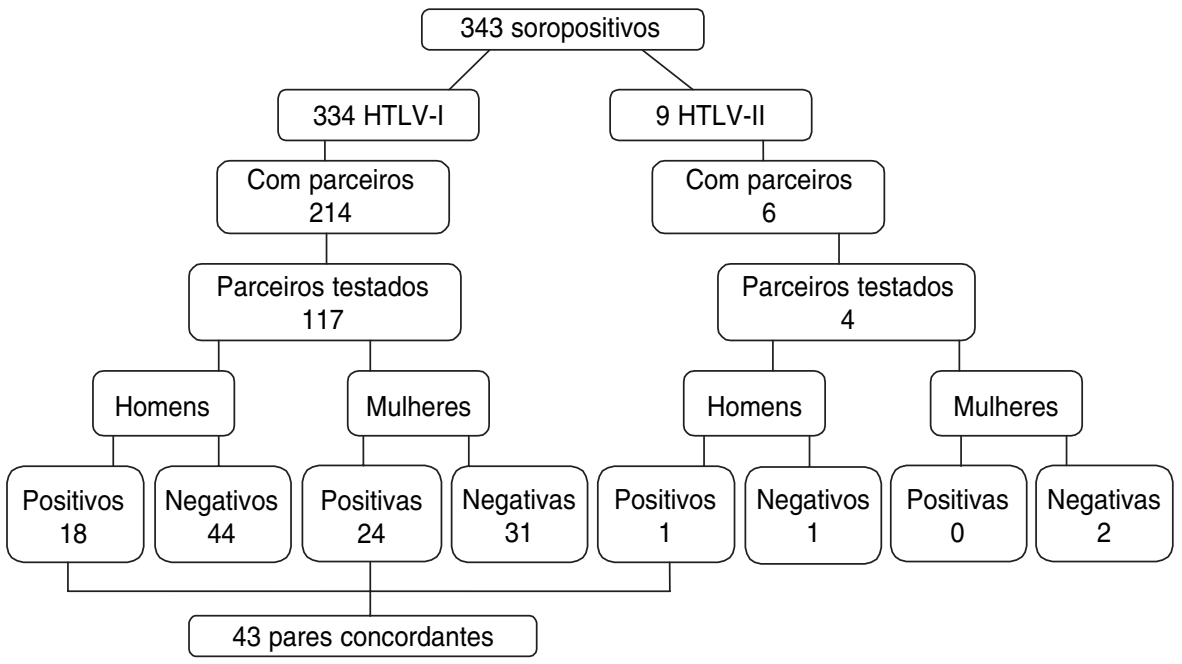

${ }^{a}$ HTLV-I e II: vírus-T linfotrópico humano dos tipo I e II. tipo I, $29,0 \%(18 / 62)$ foram soropositivos. As duas mulheres parceiras de doadores soropositivos para o tipo II foram soronegativas para HTLV-I e II no teste ELISA. Dentre os dois homens parceiros de doadoras positivas para o HTLV-II, um foi positivo para o mesmo subtipo; o outro foi soronegativo.

Quarenta e três pares concordantes (35,5\% ou 43/121) foram constituídos a partir dos resultados sorológicos positivos pelo teste ELISA, confirmados por WB e PCR; e 61,2\% (74/121) pares discordantes foram estabelecidos pelo mesmo critério.

A direção da transmissão foi considerada como provável homem-mulher em $48,8 \%(21 / 43)$ dos casais e como provável mulher-homem em $7,0 \%$ (3/43) dos casais. Nos 44,2\% (19/43) restantes, a direção da infecção foi considerada como incerta. Quando comparados os pares concordantes com transmissão provável homem-mulher com casais discordantes nos quais o homem era positivo e a parceira era negativa, diferenças significativas não foram encontradas em termos da idade média dos homens, do tempo de relacionamento, do número de parceiros sexuais e da soropositividade da mãe (tabela 2).

\section{Transmissão vertical}

De um total de 331 filhos de mães soropositivas para o HTLV-I ou II, 194 $(58,6 \%)$ foram testados sorologicamente, caracterizando uma perda de $41,4 \%$. Sorologia positiva foi confirmada em $17,5 \%$ (34/194). A tabela 3 mostra esses resultados, assim como a distribuição de freqüência por sexo e idade da população avaliada para pos- sível transmissão vertical. Dos filhos positivos, $73,5 \%$ eram maiores de 15 anos e poderiam ser também sexualmente ativos. Entretanto, a sorologia das mães é solicitada quando não são identificados comportamentos de risco para transmissão sexual (ausência de relacionamento, uso sistemático de preservativos, parceiro soronegativo). Dos 34 filhos positivos, 24 (70,6\%) eram mulheres. Dentre os 160 filhos soronegativos, $97(60,6 \%)$ eram do sexo feminino. A diferença entre reativos e não reativos aos testes não foi estatisticamente significativa quanto ao sexo $(P=0,3)$.

\section{Núcleos familiares}

Sessenta e seis núcleos familiares com pelo menos duas pessoas infectadas pelo HTLV-I ou II foram identificados. Um dos núcleos familiares foi formado por um casal e uma filha soropositivos para o HTLV-II. Todos os demais núcleos continham indivíduos infectados pelo tipo I; 60 dessas famílias continham apenas portadores assintomáticos do vírus. Em seis outras existiam casos de mielopatia associada ao HTLV (paraparesia espástica tropical) ou leucemia/linfoma de células $\mathrm{T}$ do adulto em algum dos infectados pelo HTLV-I ou II. De um total de 65 núcleos familiares infectados pelo
TABELA 2. Comparação entre casais com parceiros soropositivos para HTLV-I e casais com parceiros que apresentam diagnósticos discordantes, Belo Horizonte (MG), Brasil, $1997{\text { a } 2003^{a}}^{a}$

\begin{tabular}{lcccr}
\hline & $\begin{array}{c}\text { Pares } \\
\text { concordantes }^{\mathrm{b}}\end{array}$ & $\begin{array}{c}\text { Pares } \\
\text { discordantes }^{\mathrm{c}}\end{array}$ & OR (IC95\%) & $P^{\mathrm{d}}$ \\
\hline $\begin{array}{l}\text { Idade média dos homens } \\
\quad \text { (anos) }\end{array}$ & $39,7(21,0 \text { a } 52,0)^{\mathrm{e}}$ & $36,7(19,0 \text { a } 55,0)^{\mathrm{e}}$ & & $>0,05$ \\
$\begin{array}{l}\text { Tempo médio de } \\
\text { relacionamento (anos) }\end{array}$ & $15,3(6,0$ a 25,0) & $10,9(1,0 \text { a } 30,0)^{\mathrm{e}}$ & & $>0,05$ \\
$\begin{array}{l}\text { Transfusão de sangue } \\
\quad \text { pregressa }\end{array}$ & $3(14,3 \%)$ & $7(21,8 \%)$ & $0,60(0,10$ a 3,11$)$ & 0,40 \\
10 ou mais parceiras sexuais & $11(52,4 \%)$ & $15(46,9 \%)$ & $1,25(0,36$ a 4,34$)$ & 0,71 \\
Mãe soropositiva & $4(19,0 \%)$ & $3(9,4 \%)$ & $2,27(0,36$ a 14,98$)$ & 0,33 \\
\hline
\end{tabular}

a HTLV-I: vírus-T linfotrópico humano tipo I.

${ }^{\mathrm{b}}$ Homem e mulher soropositivos para HTLV-I, com direção provável de transmissão homem-mulher. $\mathrm{n}=21$.

c Homem soropositivo para HTLV-I e mulher soronegativa. $n=32$.

d Teste Z para comparação de médias; qui-quadrado para proporções.

e Amplitude da idade e do tempo de relacionamento entre parênteses. 
TABELA 3. Sorologia em filhos amamentados por mães soropositivas para HTLV-I e II, Belo Horizonte (MG), Brasil, 1997 a $2003^{\mathrm{a}}$

\begin{tabular}{|c|c|c|c|c|c|c|}
\hline \multirow[b]{2}{*}{ Soropositividade } & \multicolumn{2}{|c|}{ Sexo masculino $^{b}$} & \multicolumn{2}{|c|}{ Sexo feminino ${ }^{c}$} & \multicolumn{2}{|c|}{ Total $^{\mathrm{d}}$} \\
\hline & No. & $(\%)$ & No. & $(\%)$ & No. & $(\%)$ \\
\hline \multicolumn{7}{|l|}{ HTLV-I } \\
\hline$>5$ anos & 0 & & 0 & & 0 & \\
\hline 5 a 10 anos & 1 & $(1,4)$ & 3 & $(2,5)$ & 4 & $(2,1)$ \\
\hline 11 a 15 anos & 2 & $(2,8)$ & 2 & $(1,7)$ & 4 & $(2,1)$ \\
\hline$>15$ anos & 7 & $(9,6)$ & 18 & $(14,9)$ & 25 & $(12,9)$ \\
\hline HTLV-II & 0 & & 1 & $(0,8)^{e}$ & 1 & $(0,5)$ \\
\hline Total & 10 & $(13,7)$ & 24 & $(19,9)$ & 34 & $(17,5)$ \\
\hline
\end{tabular}

${ }^{a}$ HTLV-I e II: vírus-T linfotrópico humano dos tipo I e Il. A informação se refere aos 194 filhos de mães soropositivas testados para HTLV, de um total de 331 filhos elegíveis.

b $n=73$.

${ }^{c} n=121$.

${ }^{d} n=194$

e Idade: 7 anos. Mãe soropositiva para HTLV-II.
HTLV-I, provável transmissão exclusivamente horizontal foi detectada em $55,4 \%$ (35/65); provável infecção exclusivamente vertical em $27,7 \%$ (8/65); e ambas as vias de transmissão em $18,5 \%$ $(12 / 65)$ dos núcleos. No único núcleo infectado pelo HTLV-II constatamos transmissão vertical e horizontal. A figura 2 mostra o heredograma de um núcleo familiar com transmissão vertical e horizontal do HTLV-I.

\section{DISCUSSÃO}

Evidenciou-se no presente trabalho a agregação da infecção por HTLV em familiares e parceiros sexuais de porta- dores assintomáticos, aqui representados por indivíduos em quem a presença do vírus foi detectada pelo teste sorológico de triagem de banco de sangue. A taxa de prevalência encontrada, de $25,9 \%$, foi várias vezes maior do que a taxa encontrada para a população de candidatos a doação de sangue, pois a média para o Estado de Minas Gerais aponta para níveis de $0,1 \%$ nesses indivíduos.

Estudos têm mostrado alta prevalência de infecção entre familiares de indivíduos soropositivos para HTLV-I, mas principalmente em famílias que apresentam indivíduos com diagnósticos de paraparesia espástica tropical ou leucemia/linfoma de células $\mathrm{T}$ do
FIGURA 2. Heredograma de um núcleo familiar com transmissão vertical e horizontal do HTLV-I, Belo Horizonte (MG), Brasil ${ }^{\mathrm{a}}$

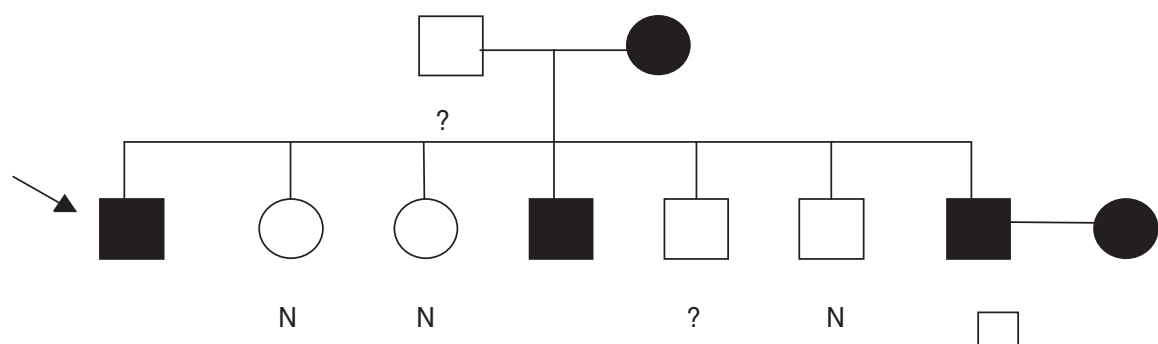

${ }^{a}$ HTLV-I: vírus-T linfotrópico humano tipo I. Os quadrados representam homens; os círculos representam mulheres. A cor preta indica positividade para HTVL-I; $N=$ negatividade para HTLV-I; ? = diagnóstico ignorado; a seta representa 0 caso índice. Todos os indivíduos eram assintomáticos. adulto. No Chile, a taxa global da infecção por HTLV-I entre familiares de pacientes com paraparesia espástica foi 30 vezes maior do que na população geral (23). Um estudo brasileiro evidenciou agregação de infecção por HTLV-I e patologias relacionadas em familiares de pacientes com leucemia/ linfoma de células $\mathrm{T}$ (25).

Há poucas informações divulgadas sobre a transmissão a partir de portadores assintomáticos. Um estudo envolvendo familiares de 20 doadores de sangue soropositivos para HTLV-I em Taiwan encontrou prevalência geral de $38,8 \%$ (26). Uma pesquisa entre familiares de gestantes soropositivas no Japão mostrou uma prevalência de infecção por HTLV-I de $41,7 \%$ entre os familiares.

No limite do nosso conhecimento e da literatura consultada, este é o primeiro estudo de familiares de portadores assintomáticos do HTLV-I e II no Brasil. A coorte GIPH acompanha também doadores com sorologia considerada indeterminada para o HTLV-I e II, ou seja, com teste imunoenzimático positivo e bandas positivas no WB, sem contudo preencherem critérios de soropositividade. Provavelmente, a maioria desses indivíduos não se encontra infectada, mas alguns podem estar a caminho da soroconversão. Alguns casos de soroconversão já estão bem documentados nesse grupo, principalmente quando existem outros casos soropositivos no núcleo familiar (dados não mostrados).

Neste artigo, mães e filhos de doadores soropositivos foram analisados separadamente para enfatizar o papel do portador assintomático como referência na identificação de outros casos soropositivos. Porém, se somados mães e filhos de doadores soropositivos, a prevalência no grupo é de $20,9 \%$. Tal prevalência é significativa e muito mais elevada $(P=0,02)$ do que a prevalência de $3,8 \%$ observada no grupo soroindeterminado, e representa a provável taxa de transmissão vertical no grupo soropositivo.

Prevalência semelhante à encontrada no presente estudo para filhos de doadoras soropositivas $(17,5 \%)$ foi relatada em estudo conduzido em Taiwan $(18,8 \%)$ (26). Em 82 filhos de pa- 
cientes com leucemia/linfoma de células $\mathrm{T}, 12 \%$ foram soropositivos para HTLV-I no Brasil (25). Um estudo conduzido na Guiana Francesa encontrou prevalência de 9,7\% entre filhos de 81 mães soropositivas (28). Os grupos de familiares dos soropositivos e dos soroindeterminados apresentaram tamanho diferente, refletindo, provavelmente, maior motivação dos portadores do vírus no recrutamento dos indivíduos a eles relacionados. Os dados não foram estratificados por sexo em virtude do pequeno tamanho da amostra para o grupo de indeterminados.

Somente um dos núcleos familiares foi formado por um casal e uma filha soropositivos para o HTLV-II, indicando possibilidade de transmissão vertical e horizontal nessa família. Vale lembrar que os usuários de drogas injetáveis são excluídos da doação de sangue, o que pode ter contribuído para a menor prevalência do HTLV-II no estudo. Embora a importância da transmissão vertical do tipo I esteja clara desde 1985, a partir do estudo prospectivo de Hino et al. (29), só mais recentemente é que evidências moleculares confirmaram a mesma via de transmissão para o tipo II (30).

A transmissão horizontal desempenhou importante papel no grupo avaliado, sendo a via mais significativa de disseminação, contrariando o resultado de um estudo conduzido entre familiares de portadores assintomáticos e pacientes com paraparesia espástica no Zaire (31) e no Japão (32), que indicam a transmissão vertical como principal via de propagação do HTLV-I. Já em Taiwan, os resultados de estudo ali conduzido com familiares de doadores de sangue apontam também a transmissão sexual como mais importante do que a vertical (26).

A predominância da transmissão homem-mulher está em concordância com outros estudos (19), e foi sete vezes mais freqüente do que a provável direção mulher-homem. Os homens transmissores eram mais velhos e tinham relacionamentos mais longos do que os homens dos pares discordantes. Compararam-se fatores de risco que pudessem prever maior carga proviral, como por exemplo transfusão de sangue pregressa e infecção desde o período pré-natal; mas as diferenças quanto a esses aspectos entre pares concordantes e discordantes não foram significativas. Comparações entre transmissão sexual do HTLV-I e do HTLV-II não foram feitas em virtude do pequeno número de casos de indivíduos infectados pelo subtipo II nessa população.

A transmissão vertical também foi significativa. Entre as crianças amamentadas por doadoras soropositivas, a infecção foi mais prevalente no sexo feminino. Embora um estudo conduzido na Guiana Francesa (28) tenha relatado a mesma observação, o tamanho da presente amostra limita as conclusões. O trabalho conduzido na Guiana Francesa encontrou associação entre títulos de anticorpos e carga proviral com a soropositividade em crianças. Não foi possível aferir o tempo de amamentação, já que apenas uma minoria dos participantes estava segura quanto a esse aspecto, e o viés de memória ou informação comprometeria a interpretação dos resultados.

Dentre as limitações do presente estudo devemos considerar as perdas na população elegível, em torno de $40 \%$. Acreditamos que elas tenham sido devidas principalmente ao fato de o recrutamento ter sido feito pelo próprio doador infectado, que muitas vezes prefere omitir ou minimizar seu diagnóstico, temendo a estigmatização por parte de seus familiares ou parceiros; ainda muita confusão é feita entre o HTLV e o HIV. O medo de represálias por faltas no trabalho foi citado por alguns participantes da coorte para justificar a não submissão de seus familiares ou parceiros aos testes. Outra possível razão para perdas é a dificuldade de pessoas assintomáticas se dirigirem à instituição onde foi realizada a pesquisa, tendo limitação de recursos financeiros até para pagar a passagem de ônibus. Perdas em torno de $40 \%$ da população elegível foram relatadas em outros estudos familiares (33). Não houve diferença estatística entre $\mathrm{O}$ grupo de familiares e parceiros sexuais testados e o grupo das perdas em relação à distribuição de freqüência de sexo. Outra limitação que deve ser con- siderada no presente trabalho é o autorelato dos pacientes quando do levantamento dos fatores de risco, através do questionário epidemiológico.

\section{CONCLUSÕES}

O presente estudo fornece evidências de agregação familiar da infecção por HTLV-I e II entre pessoas relacionadas a portadores assintomáticos. A transmissão sexual foi a forma mais provável de disseminação do vírus na população estudada. A formação de 66 núcleos familiares, além de mostrar a eficiência da transmissão entre assintomáticos, possibilitará estudos de epidemiologia genética.

As medidas para prevenir a disseminação dos vírus-T linfotrópicos humanos devem ser enfatizadas, pois não existem maneiras efetivas de controlar a leucemia de células $\mathrm{T}$ do adulto ou a paraparesia espástica tropical. Indivíduos soropositivos devem ser aconselhados para evitar a disseminação do vírus. A disponibilização do teste de HTLV-I e II para familiares de indivíduos infectados, a introdução desse teste no pré-natal e o aconselhamento e acompanhamento dos infectados em centros de referência são necessários para, juntamente com a triagem dos doadores de sangue, evitar a disseminação silenciosa do HTLV.

Agradecimentos. O presente estudo teve financiamento da Coordenação de Aperfeiçoamento de Pessoal de Nível Superior (CAPES), da Fundação de Amparo à Pesquisa do Estado de Minas Gerais (FAPEMIG), do Conselho Nacional de Desenvolvimento Científico e Tecnológico (CNPq) e da Fundação Hemominas. Grupo Interdisciplinar de Pesquisas em HTLV: Regina Amarante, Gustavo Eustáquio Brito-Melo, Bóris Cruz, Cibele Eponina Sanches Ferreira, Antônio Carlos Guedes, Maria Sueli Namen Lopes, Marina Lobato Martins, Olindo Assis Martins, Vandack Nobre, Olga Maria Carvalho Pfeilsticker, Lenice de Oliveira Piedade, Ronaldo Portela, João Gabriel Ribas, Edel Barbosa Stancioli e Bárbara Perdigão Stumpf. 


\section{REFERÊNCIAS}

1. Poiez BJ, Ruscetti FWI, Gazdar AF, Bunn PA, Minua JD, Gallo RC. Detection and isolation of type-C retrovirus particles from fresh and cultured lymphocytes of a patient with cutaneous T-cell lymphoma. Proc Natl Acad Sci USA. 1980;77(12):7415-9.

2. Murphy EL, Hanchard B, Figueroa JP, Gibbs WN, Lofters WS, Blattner WA. Modelling the risk of adult T-cell leukemia/lymphoma in persons infected with human T-lymphotropic virus type I. Int J Cancer. 1989;43(2):250-3.

3. Gessain A, Gout O. Chronic myelopathy associated with human T-lymphotropic virus type I (HTLV-I). Ann Intern Med. 1992;117 (11):933-46.

4. Mochizuki M, Watanabe T, Yamagushi K, Yoshimura K, Nakashima S, Shirao M, et al. Uveitis associated with human T-cell lymphotropic virus type I. Am J Ophthalmol. 1992;114(2):123-9.

5. Nishioka K. HTLV-I arthropathy and Sjogren syndrome. J Acquir Immune Defic Syndr Hum Retrovirol. 1996;13(Suppl 1):S57-62.

6. Gonçalves DU, Guedes AC, Proietti AB, Martins ML, Poietti FA, Lambertucci JR. Interdisciplinary HTLV-I/II Research Group. Dermatological lesions in asymptomatic blood donors seropositive for human $\mathrm{T}$ cell lymphotropic virus type-I. Am J Trop Med Hyg. 2003;68(5):562-8.

7. Adedayo AO, Grell GA, Bellot P. Case study: fatal strongyloidiasis associated with human T-cell lymphotropic virus type I infection. Am J Trop Med Hyg. 2001;65(5):650-1.

8. Kalyanaraman VS, Sarngadharan MG, Robert-Guroff M, Miyoshi I, Golde D, Gallo RC. A new subtype of human T-cell leukemia virus (HTLV-II) associated with a T-cell variant of hairy cell leukemia. Science. 1982;218 (4572):571-3.

9. Murphy EL, Fridey J, Smith JW, Engstrom J, Sacher RA, Miller K, et al. HTLV associated myelopathy in a cohort of HTLV type I and II infected blood donors. Neurology. 1997;48(2): $315-20$.

10. de Thé GD, Bomford R. An HTLV-I vaccine: why, how, for whom? AIDS Res Hum Retroviruses. 1993;9(5):381-6.

11. Carneiro-Proietti ABF, Catalan-Soares BC, Proietti FA, Interdisciplinary HTLV-1/II Research Group. Human T cell lymphotropic viruses (HTLV-I/II) in South America: should it be a public health concern? J Biomed Sci. 2002;9(6 Pt 2):587-95.

12. Proietti FA, Lima-Martins MVC, Passos VMA, Brener S, Carneiro-Proietti ABF. HTLV-I/II seropositivity among eligible blood donors from Minas Gerais State, Brazil. Vox Sang. 1994;67(1):77.

13. Catalan-Soares BC, Carneiro-Proietti ABF, Proietti FA, Interdisciplinary HTLV-I/II Re- search Group. HTLV-I/II and blood donors: determinants associated with seropositivity in a low risk population. Rev Saude Publica. 2003;37(4):470-6.

14. Hirata M, Hayashi J, Noguchi A, Nakashima K, Kajiyama W, Sawada T, et al. The effects of breastfeeding and presence of antibody to p40tax protein of HTLV-I on mother-to-child transmission. Int J Epidemiol. 1992;21(5):989_ 94.

15. Rouet F, Herrmann-Storck C, Courouble G, Deloumeaux J, Madani D, Strobel M. A casecontrol study of risk factors associated with human T-cell lymphotropic virus type-I seropositivity in blood donors from Guadeloupe, French West Indies. Vox Sang. 2002;82 (2):61-6.

16. Kajiyama W, Kashiwagi S, Ikematsu H, Hayashi J, Nomura H, Otochi K. Intrafamilial transmission of adult $\mathrm{T}$ cell leukemia virus. J Infect Dis. 1986;154(5):851-7.

17. Yanagihara R, Jenkins CL, Alexander SS, Mora CA, Garruto RM. Human T lymphotropic virus type I infection in Papua New Guinea: high prevalence among the Hagahai confirmed by western analysis. J Infect Dis. 1990;162(3):649-54.

18. Kayembe K, Goubau P, Desmyter J, Lietinck R, Carton H. A cluster of HTLV-I associated tropical spastic paraparesis in Equateur (Zaire): ethnic and familial distribution. J Neurol Neurosurg Psychiatry. 1990;53(1): 4-10.

19. Kaplan JE, Khabbaz FR, Murphy EL, Hermansen S, Roberts C, Lal R, et al. Male-tofemale transmission on human T-cell lymphotropic virus types I and II: association with viral load. J Acquir Immune Defic Syndr Hum Retrovirol. 1996;12(2):193-201.

20. Arango C, Rugeles MT, Concha M, Borrero II, Lal H, Lai S, et al. Risk factors for HTLV-I mother-to-child transmission: influence of genetic markers. Braz J Infect Dis. 1998;2(3): $135-42$.

21. Manns A, Hanchard B, Morgan OSC, Wilks R, Cranston B, Nam J, et al. Human leukocyte antigen class II alleles associated with HTLVI infection and ATLL in a Black population. J Natl Cancer Inst. 1998;90(8):617-22.

22. Plancoulaine $S$, Buigues RP, Murphy EL, van Beveren M, Pouliquen JF, Joubert M, et al. Demographic and familial characteristics of HTLV-I infection among an isolated, highly endemic population of African origin in French Guiana. Int J Cancer. 1998;76(3):331- 6.

23. Cartier L, Ramírez VE, Galeno AH. Forma familiar de la paraparesia espástica tropical: estudio de cuatro familias. Rev Med Chil. 1998; 126(4):419-26.

24. Olaleye DO, Omotade OO, Sheng Z, Adeyemo AA, Idaibo GN. Human T-cell lym- photropic virus types I and II infections in mother-child pairs in Nigeria. J Trop Pediatr. 1999;45(2):66-70.

25. Pombo-de-Oliveira MS, Carvalho SMF, Borducchi D, Dobbin J, Salvador J, Correa RB, et al. Adult T-cell leukemia/lymphoma and cluster of HTLV-I associated diseases in Brazilian settings. Leuk Lymphoma. 2001;42 (1-2):135-44.

26. Lu SC, Kao CL, Chin LT, Chen JW, Yang CM, Chang $\mathrm{AC}$, et al. Intrafamilial transmission and risk assessment of HTLV-I among blood donors in southern Taiwan. Kaohsiung J Med Sci. 2001;17(3):126-32.

27. Catalan-Soares BC. HTLV infection in public Brazilian blood centers and intravenous drug users (UDI): considerations about prevention. Em: Schatzmayr HG, Gaspar AMC, Kroon EG, eds. Proceedings of the XII National Meeting of Virology. Águas de Lindóia: Sociedade Brasileira de Virologia; 2002. Virus Reviews and Research 2002;7(1 Suppl 1):45-6.

28. Ureta-Vidal A, Angelin-Duclos C, Tortevoye $\mathrm{P}$, Murphy E, Lepére JF, Buigres RP, et al. Mother-to-child transmission of HTLV-I: implication of high antiviral antibody titer and high proviral load in carrier mothers. Int J Cancer. 1999;82(6):832-6.

29. Hino S, Yamagushi K, Katamine S, Sugiyama $\mathrm{H}$, Amagasaki T, Kinoshita K, et al. Motherto-child transmission of human T-cell leukemia virus type I. Jpn J Cancer Res. 1985; 76(6):474-80.

30. Ishak R, Vallinoto ACR, Azevedo VN, Lewis M, Hall W, Ishak MOG. Molecular evidence of mother-to-child transmission of HTLV-c in the Kararao Village (Kayapo) in the Amazon Region of Brazil. Rev Soc Bras Med Trop. 2001;34:519-25.

31. Liu HF, Vandamme AM, Kazadi K, Carton $\mathrm{H}$, Desmyter J, Goubau P. Familial transmission and minimal sequence variability of human T cell lymphotropic virus. AIDS Res Hum Retroviruses. 1994;10(9):1135-42.

32. Shimizu K. High prevalence of HTLV-I infection among the family members of a patient with ATLL from northeastern Japan. Am J Hematol. 1999;61(1):78-81.

33. Becher H, Schmidt S, Chang-Claude J. Reproductive factors and familial predisposition for breast cancer by age 50 years. A case-controlfamily study for assessing main effects and possible gene-environment interaction. Int $\mathrm{J}$ Epidemiol. 2003;32(1):38-48.

Manuscrito recebido em 11 de novembro de 2003. Aceito em versão revisada em 24 de maio de 2004 
ABSTRACT Objective. To investigate human T-cell lymphotropic virus transmission among family members of asymptomatic carriers identified through blood donor

Human T-cell lymphotropic virus in family members of seropositive blood donors: silent dissemination screening tests; and to determine the most likely direction of transmission in sexual partners having the same (concordant) serological diagnosis.

Methods. Between March 1997 and June 2003 the relatives and steady sexual partners of seropositive, asymptomatic blood donors were investigated for the presence of human T-cell lymphotropic virus types I and II. Diagnosis was based on enzyme-linked immunoassay and Western blot. To determine the direction of transmission, demographic and behavioral data were obtained through questionnaires. All participants lived in the metropolitan region of Belo Horizonte, capital of the state of Minas Gerais, Brazil.

Results. The overall prevalence of infection with human T-cell lymphotropic virus type I was $25.9 \%$ among 352 relatives of 343 seropositive patients. The prevalence rates in mothers, sexual partners, and children of seropositive donors were $36.6 \%$ (15/41), 35.9\% (42/117), and 17.5\% (34/194), respectively. The demographic and behavioral data obtained suggest greater efficiency of male-tofemale transmission.

Conclusions. The observed prevalence rates suggest there is familial aggregation of human T-cell lymphotropic virus infection. The main transmission mode was horizontal (sexual). It is important to identify the presence of the virus in family members of infected individuals, even if they are asymptomatic. Doing so may lead to a better understanding of how the virus spreads and to more efficient measures for preventing disease transmission.

\title{
Conference of the International Society of Travel Medicine
}

\author{
Dates: $\quad$ 1-5 May 2005 \\ Location: Lisbon Congress Centre \\ Lisbon, Portugal
}

The 9th Conference of the International Society of Travel Medicine (ISTM) will take a global perspective in addressing the health needs of international travelers and migrants. Attendees will include physicians, nurses, pharmacists, and students involved in primary care, occupational health, migrant health, infectious diseases, emergency medicine, and wilderness medicine. Conference plenary sessions will cover such topics as the International Health Regulations, respiratory infections and the traveler, and vivax malaria. Symposia will feature lectures by leading experts discussing topics ranging from current vaccination issues and malaria prevention to traveler's diarrhea and parasitic diseases of importance to travelers. There will also be scenario-based workshops on such subjects as yellow fever, rabies vaccine, the pregnant or breast-feeding traveler, and altitude illness.

The registration fee for ISTM member physicians is 495 euros (US\$ 659) if paid by 31 March 2005 and 595 euros (US\$ 792) if paid after that date. The respective fees for physicians who are not ISTM members are 595 euros (US\$ 792) and 695 euros (US\$ 925). There are lower fees available for nurses and students.

Information:

ISTM Europe Office

c/o International Health

Georgenstr. 5

80799 Munich, Germany

Telephone: 498934020966

Fax: 4989336038

E-mail: cistm9@istm.org

Web site: www.istm.org 